\title{
O Turismo como ferramenta para promover o desenvolvimento social e a preservação do meio ambiente em Piraquara (Paraná, Brasil)
}

\section{Tourism as a tool to promote social development and the preservation of the environment in Piraquara (Paraná, Brazil)}

\author{
Fabiana Alves Monteiro (MONTEIRO, F. A.)
}

\begin{abstract}
RESUMO - O presente trabalho tem como objetivo discutir a partir de uma revisão de literatura referente à temática, como a prática da atividade turística poderia contribuir para a valorização e conservação do Patrimônio Natural e Histórico-Cultural de uma localidade, bem como para o seu desenvolvimento econômico. Tendo como recorte espacial o município de Piraquara, integrante da Região Metropolitana de Curitiba (RMC), procurou-se demonstrar primeiramente as particularidades da sua criação e desenvolvimento, sua condição socioeconômica no contexto da Metrópole de Curitiba e como seus atrativos turísticos vêm sendo fomentados pela gestão municipal nas últimas décadas. A partir do exposto, fica evidente a importância do desenvolvimento do Turismo para o município e como sua prática vem contribuindo para o melhoramento nas suas condições socioculturais e econômicas.
\end{abstract}

Palavras-chave: Turismo; Meio Ambiente; Patrimônio Histórico e Cultural; Atrativos turísticos; Desenvolvimento.

ABSTRACT - This paper aims to discuss using a literature review on the subject, how the practice of tourism could contribute to the valorization and conservation of the Natural and Historic-Cultural Heritage of a place, as well as to its economic development. The spatial cutout was Piraquara, a city in the Metropolitan Region of Curitiba (RMC), where it was sought to demonstrate first the peculiarities of its creation and development, its socioeconomic condition in the context of the Curitiba Metropolis and how its tourist attractions have been fomented by the government management in recent decades. From what was studied, it is evident the importance of the tourism development for the municipality and how this practice has contributed to the improvement of its socio-cultural and economic conditions.

Key words: Tourism; Environment; Historic-Cultural Heritade; Tourist attractions; Development.

\footnotetext{
* Formação acadêmica: Graduação em Geografia pela Universidade Federal do Paraná (UFPR), Mestrado em Geografia, pela Universidade Federal do Paraná, Doutoranda em Geografia pelo Programa de PósGraduação em Geografia, da Universidade Federal do Paraná. Atividade Profissional: Docente pela rede estadual de educação do Paraná (SEED). Endereço físico para correspondência: Rua Danilo Pedro Schereiner, 461. CEP: 81850-250 - Curitiba - Paraná - Brasil. E-mail: fabianamot@ hotmail.com
} 


\section{INTRODUÇÃO}

A atividade do Turismo vem sendo reconhecida nas últimas décadas como uma aliada do Desenvolvimento Sustentável e como uma ferramenta fundamental para o resgate, preservação e valorização do Patrimônio Natural e Histórico-Cultural. Todavia, os estudiosos dessa temática ressaltam que essa atividade deve vir acompanhada, dentre outras premissas, de uma infraestrutura adequada na localidade ou região, da participação da comunidade local no seu desenvolvimento e da preservação dos recursos naturais.

A partir dessa abordagem, no presente trabalho se busca analisar a atividade turística no município de Piraquara, integrante da Região Metropolitana de Curitiba (RMC), evidenciando como ela se desenvolveu nas últimas décadas e quais estavam sendo os atrativos turísticos explorados pela gestão municipal.

Como atrativo turístico, Bahl (2004a), entende que são todos os elementos que possam despertar a curiosidades dos turistas. Contudo, afirma que estes atrativos não se sustentam sozinhos, havendo necessidade de agregar a eles outros atrativos semelhantes, além de facilidades que possam garantir a permanência e o deslocamento do visitante na localidade. Tais atrativos constituem a base da oferta turística, conforme aponta do autor, se configurando como um estímulo para que o turista se desloque e permaneça no local de destino.

Nesse sentido, pode-se afirmar que o município de Piraquara vem apresentando alguns atrativos turísticos relacionados ao Meio Ambiente e ao seu Patrimônio Histórico e Cultural. Tais atrativos foram fomentados pela gestão municipal como forma de promover o Desenvolvimento Sustentável e a preservação do Meio Ambiente, sobretudo na última década.

O incentivo ao desenvolvimento do Turismo no município é segundo Bahl, Néri e Nitsche (2010), parte de uma estratégia oriunda de órgãos estaduais que em 1998 formularam uma proposta para implementar itinerários turísticos na RMC, constituindo o "Anel de Turismo da Região Metropolitana de Curitiba". No caso de Piraquara, a proposta tinha como objetivo a criação do Circuito Trentino de Turismo na Serra.

De acordo com Bahl, Néri e Nitsche (2010, p. 97), a oferta do Turismo, organizada sob a forma de itinerários na RMC estava relacionada "às temáticas das 
etnias colonizadoras da região, de inserção dos produtos locais e dos recursos naturais presentes". Dessa forma, a proposta visava exaltar as peculiaridades de cada município, de modo a diferenciar os itinerários uns dos outros, destacando assim suas vocações e atrativos locais. E em cada município, estes itinerários foram estruturados mediante diferentes processos de planejamento e gestão, contribuindo para que viessem a surgir posteriormente estratégias de interação que contribuíssem para a integração entre os empreendedores da atividade do Turismo por meio de associações, conselhos e participação de distintas organizações.

A partir do exposto acima, foi realizada uma revisão de literatura e pesquisa documental neste trabalho, buscando resgatar primeiramente alguns conceitos relacionados à atividade turística, para em seguida analisar o processo de formação, desenvolvimento e condição socioeconômica vigente no município de Piraquara. Evidenciando por fim, os atrativos turísticos naturais e histórico-culturais que estavam sendo fomentados pela gestão municipal de modo a contribuir para desenvolvimento do Turismo Sustentável nessa localidade.

\section{DESENVOLVIMENTO SOCIOECONÔMICO EM PIRAQUARA E A PRÁTICA DO TURISMO}

O município de Piraquara, localizado a leste de Curitiba, contava em 2010 com uma população de 93.279 habitantes segundo Instituto Brasileiro de Geografia e Estatística - IBGE e a estimativa do Instituto para 2018 seria de uma população de aproximadamente 111 mil habitantes (IBGE, 2018). Está dividido em dois Distritos: Sede e Guarituba e 92\% do seu território é constituído de Áreas de Proteção Ambiental (APAs). Localizam-se aí as APAs dos Rios Piraquara e Iraí, as Unidades Territoriais de Planejamento (UTP) do Itaqui e Guarituba e os Reservatórios Piraquara I, II e III, que são de crucial importância, sendo responsáveis por cerca de $50 \%$ do abastecimento de água da RMC (COMEC, 2012).

Na realização do estudo constatou-se que, em razão da sua proximidade com a Serra do Mar, Piraquara possuía uma natureza exuberante, abrigando as nascentes do Rio Iguaçu e muitas áreas de mananciais. Em seu território foi construído o primeiro 
reservatório de água de abastecimento de Curitiba, a Represa do Carvalho inaugurada no ano de 1908 e que contava então com uma adutora de $38 \mathrm{~km}$ que levava água até o Reservatório do Alto São Francisco na capital (PIRAQUARA, 2018).

Observou-se também que a presença dessas paisagens naturais expressivas no município favorecia a prática do Turismo Sustentável e de Aventura e que vem sendo explorada pela gestão local, principalmente na última década.

Em relação à importância do Turismo Sustentável, Abranja e Almeida (2009) afirmaram que essa prática é determinante para o Desenvolvimento Sustentável e que foi apenas na Conferência de Estocolmo em $1972^{1}$, que a temática do Meio Ambiente começou a ter credibilidade. Contudo, segundo os autores, o conceito de sustentabilidade só surgiu na década de 1980, tendo como premissa que uma sociedade sustentável era aquela que seria capaz de satisfazer as suas necessidades sem comprometer as demandas das futuras gerações.

Posteriormente, essa noção de sustentabilidade foi usada pelo relatório elaborado pela Comissão Mundial do Meio Ambiente e Desenvolvimento (Relatório Brundtland) ${ }^{2}$ para apresentar o conceito de Desenvolvimento Sustentável que surgiu, de acordo os autores citados acima, devido à procura de soluções para os problemas provocados pela exploração descontrolada dos recursos naturais ao longo da história da humanidade.

Os autores afirmam também que foi na Conferência das Nações Unidas para o Meio Ambiente e o Desenvolvimento (ECO 92) ${ }^{3}$, realizada na cidade do Rio de Janeiro em 1992, que o Turismo foi reconhecido como atividade capaz de criar benefícios econômicos e contribuir para o Desenvolvimento Sustentável. Sendo que na Agenda $21^{4}$, um dos legados dessa Conferência, se salienta um conjunto de objetivos e

\footnotetext{
${ }^{1}$ A Conferência das Nações Unidas (ONU) sobre o Meio Ambiente e Desenvolvimento foi realizada na cidade de Estocolmo, Suécia, no ano de 1972, onde foi recomendada a criação do Programa das Nações Unidas para o Meio Ambiente - PNUMA (NASCIMENTO, et al. 2013).

${ }^{2}$ Este Relatório, publicado no ano de 1987, apresenta uma visão crítica do programa de desenvolvimento adotado pelos países industrializados e em desenvolvimento e destacam os riscos do uso excessivo do patrimônio natural sem se preocupar com a capacidade de suporte dos ecossistemas (ABRANJA; ALMEIDA, 2009).

${ }^{3}$ De acordo com Abranja e Almeida (2009), a ECO 92, também chamada de Rio 92, teve como objetivo encontrar instrumentos que fossem capazes de compatibilizar o desenvolvimento socioeconômico com a conservação e proteção dos ecossistemas da Terra.

${ }^{4}$ Um dos resultados da Conferência das Nações Unidas para o Meio Ambiente e o Desenvolvimento, realizada no Rio De Janeiro em 1992 (Ibid).
} 
princípios fundamentados em critérios de sustentabilidade, de modo a orientar o desenvolvimento da atividade turística, tornando-a "ecologicamente correta, economicamente viável e socialmente justa". Tal Agenda reconhece também que os critérios de qualidade referentes à conservação do destino turístico e a satisfação do turista devem ser determinados em conjunto com as comunidades locais (ABRANJA; ALMEIDA, 2009, p. 23).

Já Nascimento et al. (2013), afirmaram que, com o aumento da atividade turística nas últimas décadas, ocorreu a adoção dos princípios do Turismo Sustentável em contraponto a prática predatória do Turismo e também como alternativa ao modelo de desenvolvimento econômico vigente. Além disso, a adoção do conceito de Desenvolvimento Sustentável aplicado ao Turismo representa uma estratégia para equacionar a relação entre o uso turístico do espaço, preservação do meio ambiente e melhorias nas condições de vida nas comunidades locais. Havendo, para tanto, a necessidade do aporte do estado, de modo a definir políticas setoriais que atendam aos anseios da atividade turística, o que demanda necessariamente, segundo os autores, uma gestão democrática, com a participação do poder público, entidades privadas e comunidade local, desenvolvendo assim, essa atividade de forma planejada e articulada.

Os autores ressaltam ainda a importância do planejamento nessa atividade, estabelecendo objetivos e metas e, sobretudo, o percurso a ser realizado para alcançar os mesmos. Dessa forma o desenvolvimento do Turismo requer uma gestão abrangente e visão de longo prazo, porém, ressaltam que essa atividade é prejudicada de forma rotineira pela descontinuidade das políticas públicas a cada nova gestão (NASCIMENTO, et al. 2013).

Além do incentivo a prática do Turismo Sustentável, verificou-se haver também no município o estímulo às atividades relacionadas ao Turismo Histórico e Cultural, a partir da exploração de alguns atrativos, especialmente relacionados à sua origem, colonização e costumes. Em relação aos atrativos culturais de uma localidade ou região, Bahl (2004a), afirma que estes são recursos que podem ser utilizados como elemento diferenciador, dando-lhe tonalidade própria e diferenciação em relação aos demais.

Segundo o Plano Diretor do município (2006), Piraquara foi firmada oficialmente no ano de 1890, e teve seu crescimento impulsionado com a instalação de uma estação ferroviária da Estrada de Ferro Paranaguá-Curitiba, construída na década 
de 1880. Data desse período também, a formação da única colonização de trentinotiroleses do Paraná, chamada de Colônia Imperial Santa Maria do Novo Tirol da Boca da Serra, onde seus descendentes se dedicaram a resgatar a cultura e tradições da Itália relacionadas ao Agroturismo (PIRAQUARA, 2006).

No que diz respeito aos aspectos socioeconômicos de Piraquara, o seu período de maior crescimento populacional ocorreu nas últimas décadas, com o processo de metropolização de Curitiba. Conforme aponta Firkowski (2001), esse processo tem suas origens na década de 1970 e se consolidou nos anos de 1990, tendo como uma das suas principais características a exclusão de parte da população pobre para os municípios periféricos da metrópole.

Essa época marca também um crescimento no número de assentamentos informais em áreas inadequadas à moradia, principalmente em áreas de mananciais na porção norte e leste de Curitiba, conforme atesta Lima (2000). Destacando-se nesse contexto a formação do Guarituba que no ano de 1998 foi declarada Unidade Territorial de Planejamento (UTP).

Conforme atestam Lima, Campos e Terbeck (2009), o Guarituba se constitui numa área de ocupação urbana significativa do município, superando a sede urbana em expansão, dada a influência da Estrada do Encanamento e da linha férrea, além da proximidade com Pinhais. Caracterizando-se pela presença de inúmeras sub-habitações e por sua fragilidade ambiental, em função do predomínio de solos hidromórficos e do lençol freático aflorante.

De acordo com a COHAPAR (2007), a população total da UTP no ano de 2007 - quando foi concluído o Diagnóstico Ambiental e Socioeconômico da área por essa instituição, era estimada em 44 mil pessoas e deste total, 24 mil viviam em condição irregular, sendo que mais da metade da população total não era atendida pelos serviços de abastecimento de água e rede de esgoto. É desse período também a elaboração do Projeto de Urbanização e Recuperação Ambiental do Guarituba, resultado da parceria da Prefeitura Municipal e do Governo Estadual. Tal Projeto foi incorporado no mesmo ano ao recém-lançado Programa de Aceleração do Crescimento (PAC), do Governo Federal, no eixo Habitação. Este Programa tinha como objetivo promover a urbanização e a recuperação ambiental em assentamentos de grande complexidade socioambiental por todo o país (BRASIL, 2010). 
A partir de então, conforme afirma o Ministério do Planejamento (2017) a UTP do Guarituba vem passando por intervenção do Estado e recebeu algumas melhorias, com a implantação de infraestrutura básica e instalação de dois conjuntos habitacionais para as famílias que viviam em condição de risco (BRASIL, 2017).

A UTP do Guarituba está inserida num manancial de abastecimento público, próximo ao Distrito de Pinhais que se emancipou no ano de 1992. Essa emancipação resultou, segundo Lima, Campos e Terbeck (2009, p. 274) em profundas transformações socioeconômicas em Piraquara, culminando com uma perda de " $21 \%$ do seu território e $71 \%$ da sua população". No entanto, segundo os autores, mesmo com essa perda populacional, o município apresentou no período entre 1996 a 2000 uma taxa de crescimento anual de $8,53 \%$.

Desse modo, constatou-se que alguns dos principais problemas do município relacionam-se à moradia, a poluição ambiental e a baixa arrecadação de impostos, em função de a população ser predominantemente de baixa renda e da restrição à instalação de indústrias em seu território.

Assim, entendeu-se que o incentivo à prática do Turismo Sustentável no município seria um fator positivo, ainda que Bahl (2004b) reitere que as atividades vinculadas a essa prática devem estar necessariamente identificadas à preservação da natureza e dos valores locais, sejam elas de cunho social ou cultural.

Abranja e Almeida (2009) também afirmam que a valorização da questão ambiental como fruto da qualquer atividade turística é fundamental e vai ao encontro de uma exigência do mercado, que é a proteção e conservação do Meio Ambiente. E que um empreendimento turístico sustentável deve obrigatoriamente levar em conta a adaptação de serviços essenciais, como o destino dos resíduos decorrentes da atividade turística, o saneamento básico, a infraestrutura e o abastecimento de água causando o menor impacto ambiental possível.

Além disso, verifica-se que o Turismo poderia proporcionar a geração ou complementação de renda nas comunidades locais, pois de acordo com o Ministério do Turismo (MTUR - Brasil), a perspectiva dessa atividade como meio de inclusão social é uma estratégia do Estado e foi absorvida pelos oito Objetivos do Milênio, criados no ano de 2000 pela Organização das Nações Unidas sobre o Desenvolvimento 
Sustentável $^{5}$ onde os governos foram estimulados a aproveitar ao máximo as possibilidades do Turismo, visando à erradicação da pobreza e elaborando estratégias apropriadas em colaboração com todos os grupos interessados e as comunidades locais (BRASIL, 2007).

Destaca-se também a utilização das atividades do Turismo como ferramenta de resgate, valorização e conservação do patrimônio histórico e de culturas tradicionais. Segundo Bahl (2004b), o estabelecimento de uma política cultural pode trazer benefícios de diversas ordens, baseada e calcada em algumas estratégias como: estímulo ao resgate da cultura local, da autoestima e do orgulho dos hábitos e costumes das comunidades; incentivo a conservação, manutenção e restauração da arquitetura típica e tradicional; busca por uma revalorização da gastronomia, do folclore e das tradições das localidades e regiões; fomento ao desenvolvimento de programas educativos e de esclarecimento às populações locais e regionais; entre outros.

$\mathrm{O}$ autor coloca ainda que o Turismo Cultural está relacionado a três aspectos básicos: o primeiro se refere aos tipos de elementos que podem ser trabalhados como atrativos de uma localidade e que possuam uma conotação cultural; o segundo diz respeito às atividades vinculadas ao aproveitamento destes atrativos para 0 desenvolvimento de atividades turísticas e o terceiro se refere às motivações das viagens turísticas (BAHL, 2004b, p. 33).

Entretanto, o autor ressalta que para evitar implicações sociológicas, o planejamento do turismo nas comunidades receptoras deve ser capaz de adaptar os componentes da oferta de maneira adequada, fazendo com que a população se conscientize da importância de receber adequadamente o turista de diferentes classes de renda, sob o risco de causar uma imagem inadequada da localidade e uma consequente publicidade negativa.

\footnotetext{
${ }^{5}$ O ideal de Desenvolvimento Sustentável foi semeado em 1950, quando a IUNC (Internacional Union Conservation of Nature) apresentou um trabalho onde utilizou pela primeira vez o termo "desenvolvimento sustentável", sendo que esse conceito foi oficializado em 1987 no relatório "Nosso Futuro em Comum", apresentado pela CMMAD (Comissão Mundial sobre o Meio Ambiente e Desenvolvimento), onde propunha que se deveria atender às necessidades do presente sem comprometer o atendimento às gerações futuras (BRASIL, 2007).
} 


\section{ATRATIVOS TURÍSTICOS DE PIRAQUARA}

Tendo em vista os impactos positivos do Turismo Sustentável na economia e no Meio Ambiente e a existência de alguns atrativos no município de Piraquara, constatouse que a Prefeitura investiu, sobretudo na última década, em algumas estratégias para fomentar essa atividade. Dentre elas, destaca-se segundo o Departamento de Turismo do município, a criação do Roteiro Turístico Caminho Trentino dos Mananciais da Serra na década de 2000. O Projeto para a implantação desse roteiro é do ano de 1997 e foi elaborado pelo Técnico Agrícola Gilmar Zachi Clavisso, então funcionário da Secretaria Municipal de Meio Ambiente, Agricultura e Turismo (SMAAT), em parceria com a EMATER/PR. O Departamento informa que a divulgação do Projeto ocorreu no ano de 2001, no I Fórum "Pensando na cidade" e tinha como proposta inicial, a divisão do roteiro em núcleos para visitação, que incluíam propriedades rurais, a área urbana, atrações culturais e áreas de preservação (PIRAQUARA, 2018).

No momento da pesquisa, verificou-se também, através de informações disponibilizadas pelo site oficial da Prefeitura que o Caminho Trentino incluía a porção central do município, os Mananciais da Serra e algumas comunidades como Roça Nova e Colônia Santa Maria do Novo Tirol da Boca da Serra, entre outras, conforme pode-se observar na Figura 1. No itinerário constava também a oferta de passeios a cavalo, aulas de equitação, pousadas e comércio de produtos artesanais, entre outros. No endereço eletrônico da Prefeitura havia ainda a informação que o Departamento de Turismo do município desenvolvia as seguintes atividades de modo a fomentar esse roteiro: (PIRAQUARA, 2018).

- Informações Turísticas;

- Agendamento e acompanhamento aos atrativos do município;

- Organização e realização de atividades turísticas sustentáveis;

- Organização e realização de eventos;

- Divulgação do município a nível nacional. 
FIGURA 1 - ROTEIRO TURÍSTICO CAMINHO TRENTINO DOS MANANCIAIS DA SERRA

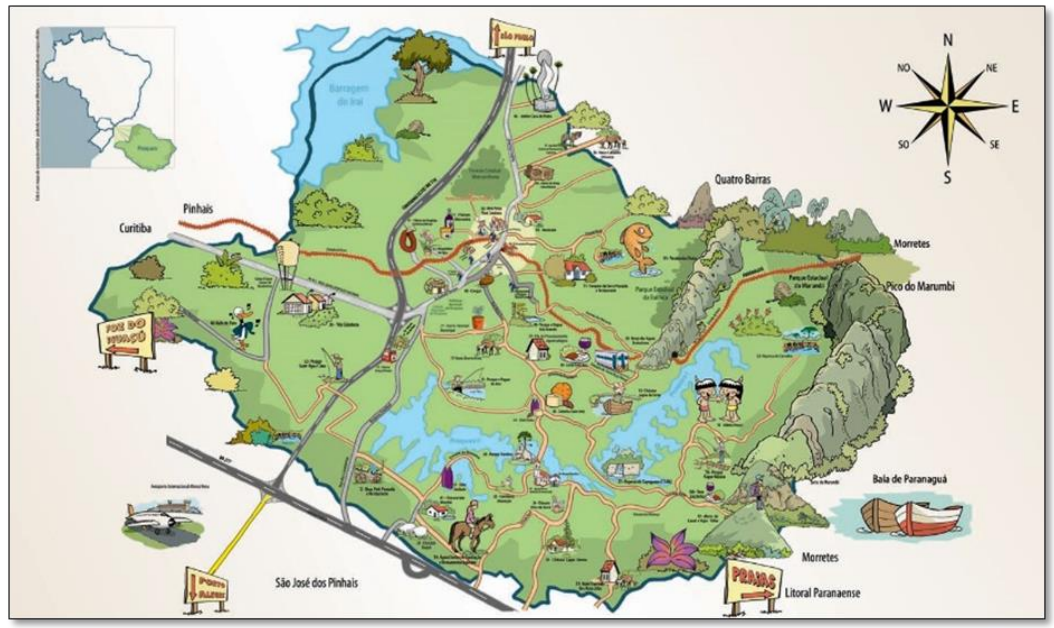

FONTE: PIRAQUARA (2018).

Entre as outras atividades incentivadas por esse Departamento, destacavam-se o Turismo de Aventura, através prática de mountain bike, caminhadas, trekking, escalada e cavalgada nos mais de $100 \mathrm{~km}$ de estradas rurais do município e da escalada do Morro do Canal.

Porém, para Dantas e Pires (2015), não há uma definição acerca do conceito de Turismo de Aventura em razão de ser um fenômeno relativamente recente e que possui uma diversidade de práticas. Além disso, o conflito na sua definição está relacionado à subjetividade da percepção de aventura e de envolver a cultura, tradições e a história, que varia de individuo para individuo.

Os autores afirmam também que o Turismo de Aventura é considerado um nicho da "indústria turística", com características similares ao Ecoturismo e ao Turismo de Natureza. Entretanto, o conceito de aventura está relacionado ao resultado incerto, ao risco, perigo e desafio, necessitando da ação e do engajamento do turista.

Observou-se também que estava ocorrendo no município a promoção de eventos e manutenção de atrações relacionadas à conservação do Meio Ambiente, como o Centro de Educação Ambiental Mananciais da Serra (CEAM). Este local foi criado no ano de 1997, junto à Barragem do Rio Cayuguava (Piraquara I) para realização de atividades educativas e de conscientização ambiental. Possui um miniauditório com capacidade para atender cerca de 30 pessoas e salas com exposições sobre a Temática ambiental e histórica da região (PIRAQUARA, 2018). 
Também se revelou como atrativo no município a Represa do Carvalho, primeiro reservatório de água da RMC, pertencente aos Mananciais da Serra, na área do Parque Estadual Pico do Morumbi. O local estava oferecendo visitas abertas em datas préestabelecidas entre os meses de abril a dezembro ou previamente agendados e os visitantes do local poderiam participar de atividades monitoradas de caminhadas e trilhas com diferentes percursos, como a Trilha da Estrada do Carvalho, com percurso de 2,5 $\mathrm{km}$ e a Trilha da Chaminé com 1,5 km de percurso (PIRAQUARA, 2018). A Figura 2 a seguir demonstra parte Centro de Educação Ambiental Mananciais da Serra e uma imagem aérea da Represa do Carvalho.

FIGURA 2 - CENTRO DE EDUCAÇÃO AMBIENTAL MANANCIAIS DA SERRA (CEAM) E REPRESA DO CARVALHO EM PIRAQUARA
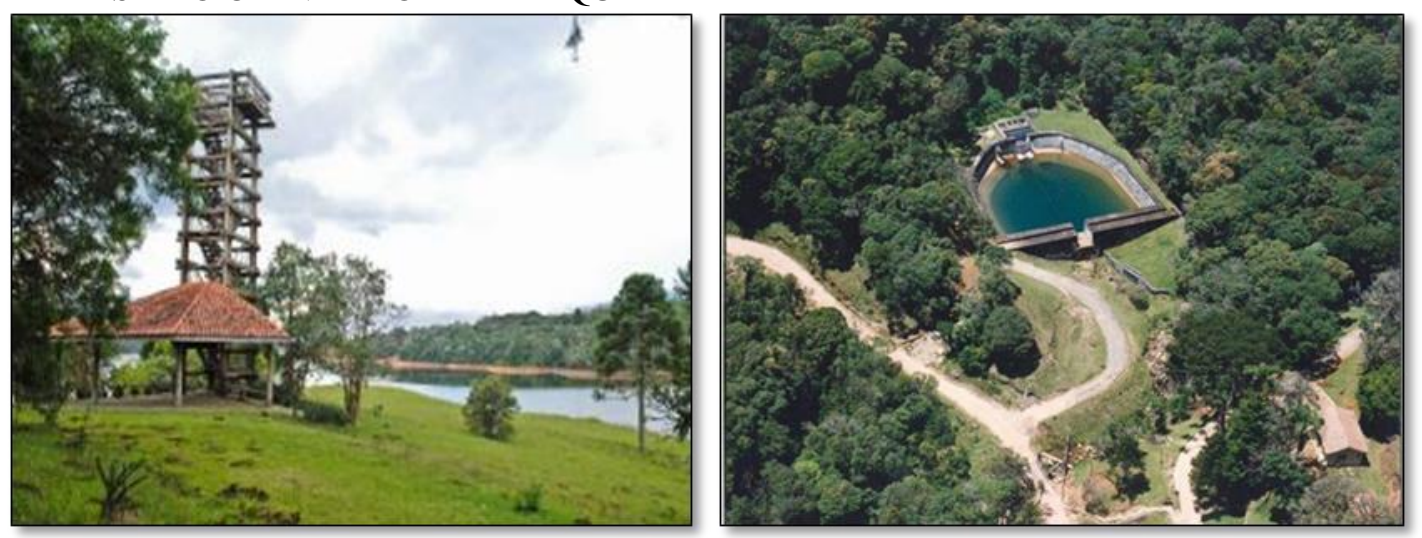

FONTE: PIRAQUARA (2018).

Como atividade turística relacionada à conservação do Meio Ambiente, o Departamento de Turismo do município (2018) destacava alguns eventos como:

- A limpeza da Represa Piraquara II com a utilização de caiaques nos meses de abril e agosto;

- A realização da caminhada internacional da natureza e da pedalada internacional da natureza que ocorrem no mês de novembro;

- A Caicada no Rio Piraquara em março;

- A Remada da Primavera na Represa Piraquara II no mês de setembro;

- E o Desafio das Águas na Represa Piraquara II com caiaques no mês de dezembro. Estas atividades estavam sendo promovidas em parceria com a Sanepar com o objetivo de desenvolver a prática de esportes náuticos não poluentes no município (PIRAQUARA, 2018). Na Figura 3 abaixo, estão representados trechos do percurso da caicada realizada no Rio Piraquara e da caminhada noturna ofertada pelo município. 


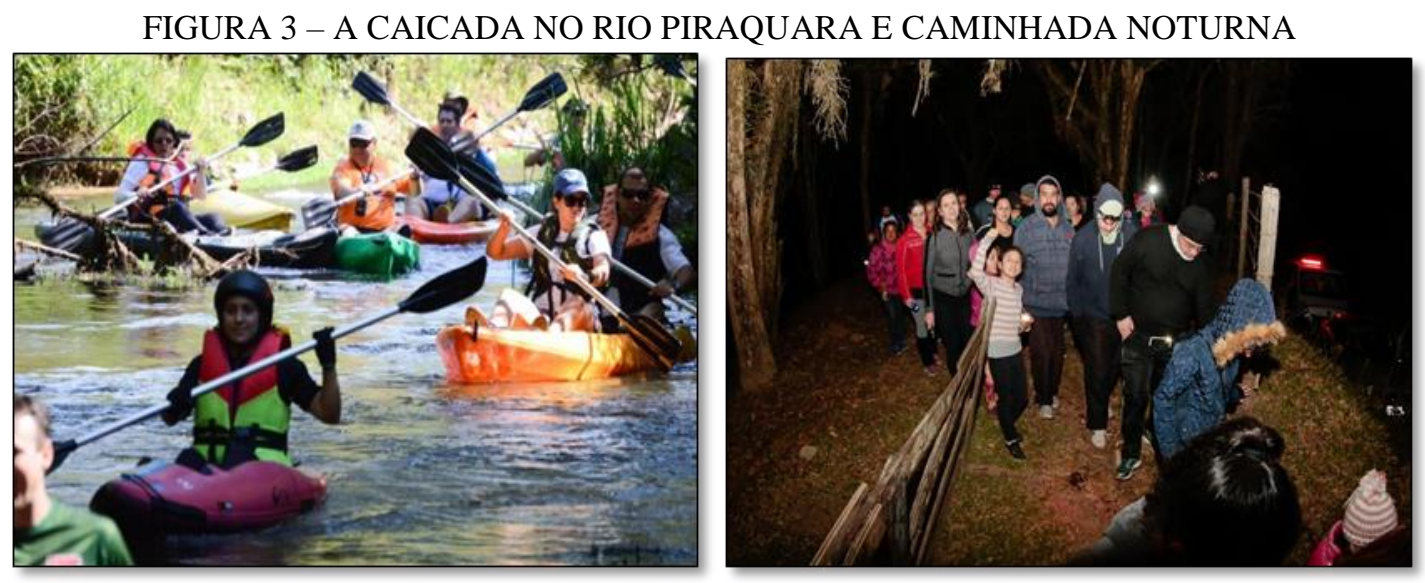

FONTE: PIRAQUARA (2018).

Já como atividades turísticas que envolvem a cultura e as tradições do município, o Departamento de Turismo estava dando ênfase à realização de festas e comemorações populares ou folclóricas como a Festa Trentina, em comemoração a imigração, a Festa de Aniversário de Piraquara e a Festa do Carneiro no Rolete, esta última, realizada no Parque Trentino, na Colônia Imperial Santa Maria do Novo Tirol da Boca da Serra. Tal Colônia foi fundada no ano de 1878 por 59 famílias imigrantes das Colônias Tirol e Trento, localizadas nas áreas montanhosas da Europa e que pertenciam na época ao Império Austro-Húngaro. O Departamento informa também que no momento, as famílias desta Colônia vêm procurando resgatar a cultura e as tradições italianas aliadas ao agroturismo (PIRAQUARA 2018).

Além disso, outra atividade turística que foi colocada em evidência no município é a gastronomia típica e que estava sendo explorada, ainda que de forma incipiente, através da implantação da Vila do Colono, voltada a produção agroecológica, orgânica e ao agroturismo. Este Projeto é coordenado pela Associação Agroecológica e Turística de Piraquara e de acordo com a Prefeitura Municipal, levou a criação da Cooperativa de Processamento Alimentar da Agricultura Solidária de Piraquara, chamada CopasolTrentina (PIRAQUARA 2018).

No município estava ocorrendo ainda um recente estímulo ao desenvolvimento do Enoturismo, atividade baseada na viagem motivada pela apreciação dos vinhos e da valorização das culturas e tradições dos locais onde a bebida é produzida (PIRAQUARA 2018). Essa atividade foi desenvolvida em Piraquara através do empreendimento Cave Colinas de Pedra, que incluía um restaurante e uma loja de espumantes localizada na Estação Roça Nova, recentemente restaurada, um vagão 
gourmet $^{6}$ e o túnel colonial construído em 1883 e que abrigava uma cave de envelhecimento de vinho espumante natural (PIRAQUARA, 2018). Parte do empreendimento Cave Colinas de Pedra está ilustrado na Figura 4 a seguir.

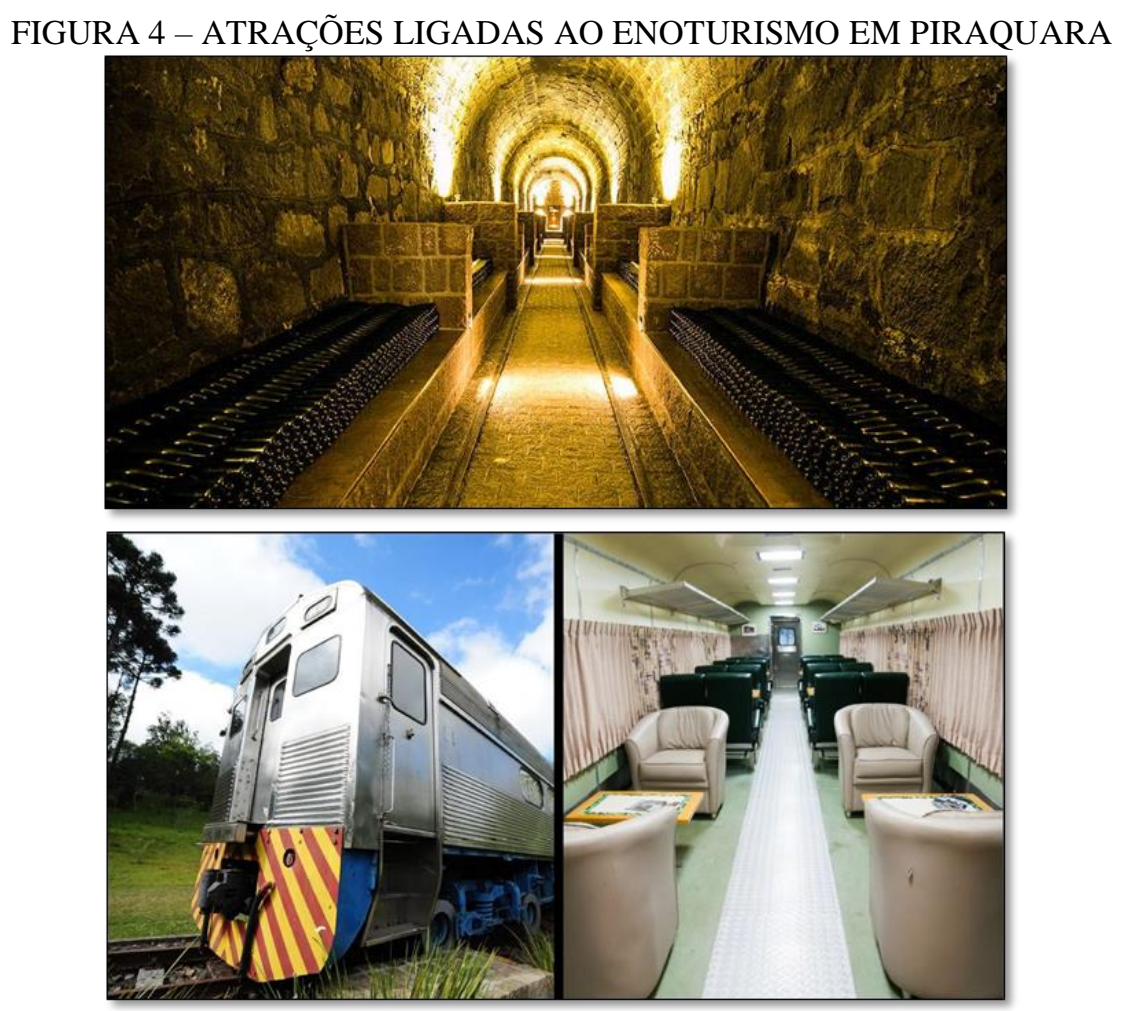

FONTE: PIRAQUARA (2018).

Considera-se dessa forma, que o incentivo a estas atividades turísticas no município estava possuindo grande relevância, todavia, cabe ressaltar novamente que a prática dessa atividade requer o investimento também em infraestrutura e a participação da população local. No caso de Piraquara, foi constatado um recente melhoramento também nesse sentido, através da adequação da infraestrutura existente, por meio de um projeto para a revitalização da área central e de implantação de infraestrutura básica no Roteiro Turístico do município.

Pois, conforme apontou a pesquisa realizada por Alves et al. (2015), realizada através de entrevistas direcionadas sobre as condições de infraestrutura do Caminho Trentino de Piraquara, houve apontamentos negativos, principalmente no que se refere a sinalização, a disponibilidade de informações turísticas pelo site da Prefeitura, a

\footnotetext{
${ }^{6}$ Essa palavra de origem francesa está relacionada gastronomia que envolve cultura e arte e é voltada a consumidores que possuem um paladar mais apurado e exigente.
} 
dificuldade de acesso ao local e/ou a periculosidade das estradas rurais, além de problemas relacionados ao eventos promovidos pela prefeitura. A autora enfatiza também que a pesquisa apontou também como sugestão dos entrevistados, uma melhoria exploração da rede hidrográfica do município, através da liberação controlada da prática de esportes náuticos, competitivos ou não.

\section{CONSIDERAÇÕES FINAIS}

A partir dessa breve discussão acerca da prática do Turismo, sobretudo o Sustentável, constatou-se sua relevância como meio de promover o desenvolvimento econômico e sociocultural de uma localidade, no caso estudado, o município de Piraquara, na Região Metropolitana de Curitiba.

Encontra-se aí metade dos reservatórios de água responsáveis pelo abastecimento da RMC e seu histórico de ocupação revela um crescimento populacional desordenado e sem o acompanhamento de infraestrutura adequada, tal como ocorreu na maioria dos municípios periféricos das grandes metrópoles do país ao longo do século passado. De modo que alguns dos seus maiores problemas estão relacionados à moradia e a degradação do Meio Ambiente.

Dessa forma, constatou-se que o incentivo às atividades relacionadas ao Turismo Sustentável pela gestão municipal é um fator positivo e constitui uma alternativa para a geração de renda e para a valorização e conservação do Patrimônio Natural e HistóricoCultural de Piraquara. Todavia, cabe ressaltar que, conforme aponta a literatura especializada, essa atividade deve estar necessariamente relacionada ao melhoramento da infraestrutura local, à participação da comunidade e à preservação do Meio Ambiente.

\section{REFERÊNCIAS}

ABRANJA, N. A.; ALMEIDA, I. D. de. Turismo e Sustentabilidade. Cogitur, Journal of Tourism Studies, [S.1.], v. 2, n. 2, 2009. Disponível em: <http://revistas.ulusofona.pt/index.php/jts/article/view/506>. Acesso em: 05/10//2018. 
ALVES, A. R.; SANTOS, L. C. R.; ROSSA, P.; PANK, R. Novas concepções da infraestrutura turística do Caminho Trentino, Piraquara - PR, sob o viés de um planejamento orientado ambientalmente, 2015. Disponível em: <https://www.researchgate.net>. Acesso em: 03/10/2018.

BAHL, M. Legados étnicos \& oferta turística. Curitiba: Juruá, 2004.

Fatores ponderáveis do Turismo: sociais, culturais e políticos. Curitiba: Protexto, 2004b.

BAHL, M.; NÉRI, L. F.; NITSCHE, L. B. Organização local de Itinerários Turísticos na região Metropolitana de Curitiba, Paraná, Brasil. Gestíon Turística, n. 13, p. 93-112, jun. 2010.

BRASIL. Ministério do Planejamento. Primeiro Balanço 2015 - Paraná. Brasília, 2017. Disponível em: <http://www.pac.gov.br/sobre-o-pac/publicacoesregionais>. Acesso em: 12/09/2018.

Ministério do Planejamento. Site oficial. Disponível em: <http://www.planejamento.gov.br>. Acesso em 03/09/2018.

BRASIL. Ministério do Turismo. Turismo sustentável e alívio da pobreza no Brasil, reflexões e perspectivas. 2007. Disponível em:

<http://www.livrosgratis.com.br/arquivos_livros/tu000017.pdf $>$. Acesso em: 15/09/2018.

BRASIL. Ministério das Cidades. Urbanização de Favelas: a experiência do PAC. Brasília, 2010. Disponível em:

<http://www.capacidades.gov.br/biblioteca/./id/.../Urbanizacao+de+favelas\%>. Acesso em: 28/04/2018.

COMPANHIA DE HABITAÇÃO DO PARANÁ (COHAPAR). Programa Direito de Morar - Guarituba. Curitiba, 2007. 20/08/2018.

Site oficial. Disponível em: 〈http://www.cohapar.pr.gov.br>. Acesso em

COORDENAÇÃO DA REGIÃO METROPOLITANA DE CURITIBA (COMEC). Revista da Região Metropolitana de Curitiba. Curitiba, 2012.

DANTAS, L. M. R.; PIRES, P. dos S. Versões e Contradições do Turismo de Aventura: reflexões sobre as atividades de aventura e sobre o turista. Turismo \& Sociedade. Curitiba, v. 8, n. 2, p. 276-300, 2015.

FIRKOWSKI, O. L. C. de F. A nova territorialidade da indústria e o Aglomerado Metropolitano de Curitiba. 225 f. Tese (Doutorado em Geografia), Faculdade de Filosofia, Letras e Ciências Humanas, Universidade de São Paulo, 2001. 
INSTITUTO BRASILEIRO DE GEOGRAFIA E ESTATISTICA (IBGE). Site oficial. Disponível em: <http://www.ibge.gov.br>. Acesso em: 29/05/2018.

LIMA, C. A. A ocupação de área de mananciais na Região Metropolitana de Curitiba: do planejamento à gestão ambiental urbana-metropolitana. $345 \mathrm{f}$. Tese (Doutorado em Meio Ambiente). Programa de Doutorado em Meio Ambiente e Desenvolvimento, Universidade Federal do Paraná, Curitiba, 2000.

LIMA, C. A.; CAMPOS, M. L. B.; TERBECK, M. I. Ocupação urbana em área de mananciais: análise de densidade e índice de ocupação como evidencias de um padrão em consolidação nos municípios de Piraquara e Pinhais - Região Metropolitana de Curitiba. In: MOURA, R; FIRKOWSKI, O. L. C. de F. Dinâmicas intrametropolitanas e produção na RMC. Letra Capital: Observatório das Metrópoles. Curitiba, p. 269-294, 2009.

NASCIMENTO, A. M. V. do; ROCHA, L. K. S; AZEVEDO, F. F. de; MORAIS, I. R. D. Turismo e transformações socioespaciais: uma aproximação teórica e conceitual. Turismo \& Sociedade. Curitiba, v. 6, n. 2, p. 388-407, 2013.

PIRAQUARA. Plano Diretor Municipal. Piraquara, 2006. 20/09/2018.

Site Oficial. Disponível em: <http://www.piraquara.pr.gov.br/>. Acesso em:

Recebido em: 24-01-2019.

Aprovado em: 23-02-2019.

Versão finalizada para publicação em: 25-03-2019. 